\title{
Erratum: The Danish investigation on iodine intake and thyroid disease, DanThyr: status and perspectives
}

Peter Laurberg, Torben Jørgensen ${ }^{2}$, Hans Perrild ${ }^{3}$, Lars Ovesen ${ }^{1,4}$, Nils Knudsen ${ }^{2,3}$, Inge Bülow Pedersen, Lone B Rasmussen ${ }^{1}$, Allan Carlé and Pernille Vejbjerg ${ }^{2,3}$

Department of Endocrinology and Medicine, Aalborg Hospital, DK-9000 Aalborg, Denmark, ${ }^{1}$ Danish Institute for Food and Veterinary Research, Copenhagen, Denmark, ${ }^{2}$ Research Centre for Disease Prevention and Health, Glostrup Hospital, Copenhagen, Denmark, ${ }^{3}$ Medical Clinic I, Bispebjerg Hospital, Copenhagen, Denmark and ${ }^{4}$ The National Heart Foundation, Copenhagen, Denmark

(Correspondence should be addressed to P Laurberg; Email: laurberg@aas.nja.dk)

The journal apologizes for an error on page 222 of the above paper, which appeared in 1552 219-228. The error occurred after proofreading.

The text incorrectly indicates that the iodine intake in Denmark after iodine fortification of salt was calculated to increase to a level of $62 \mu \mathrm{g}$ /day. The correct meaning is that the level of iodine intake was calculated to increase by $62 \mu \mathrm{g}$ iodine per day.

European Journal of Endocrinology 155643 